\title{
Cerebrospinal Fluid Studies in Kenyan Children with Severe Falciparum Malaria
}

\author{
N. Mturi ${ }^{1}$, G. Keir $^{2}$, C.A. MacLennan ${ }^{3,4}$, A. Ross ${ }^{1,5,6}$, A.C. Willis ${ }^{7}$, B.C. Elford ${ }^{8}$, J.A Berkley ${ }^{1,5}$ and \\ C.R.J.C Newton ${ }^{1,9,10, *}$
}

\begin{abstract}
${ }^{I}$ Kenya Medical Research Institute, Centre for Geographic Medicine Research (Coast), P. O. Box 230, Kilifi, Kenya; ${ }^{2}$ Department of Neuroimmunology, Institute of Neurology, Queen Square, London WCIN 3BG, UK; ${ }^{3} M R C$ Centre for Immune Regulation, Division of Immunity and Infection, University of Birmingham, Birmingham B15 2TT, UK; ${ }^{4}$ Malawi-Liverpool-Wellcome Trust Clinical Research Programme, College of Medicine, University of Malawi, Blantyre, Malawi; ${ }^{5}$ Centre for Tropical Medicine, Nuffield Department of Medicine, University of Oxford, The John Radcliffe Hospital, Oxford OX3 9DY, UK; ${ }^{6}$ Swiss Tropical Institute, Socinstrasse 57, CH-4002 Basel, Switzerland; ${ }^{7}$ MRC Immunochemistry Unit, Biochemistry, University of Oxford, Oxford, UK; ${ }^{8}$ Molecular Parasitology Group, Weatherall Institute of Molecular Medicine, John Radcliffe Hospital, Oxford OX3 9DS, UK; ${ }^{9}$ Clinical research Unit, London School of Hygiene and Tropical Medicine, London, UK and ${ }^{10}$ Neurosciences Unit, Institute of Child Health, University College London, The Wolfson Centre, Mecklenburgh Square, London, WC1N 2AP, UK
\end{abstract}

\begin{abstract}
The pathogenesis of the neurological complications of Plasmodium falciparum malaria is unclear. We measured proteins and amino acids in paired plasma and cerebrospinal fluid (CSF) samples in children with severe falciparum malaria, to assess the integrity of the blood brain barrier (BBB), and look for evidence of intrathecal synthesis of immunoglobulins, excitotoxins and brain damage.

Methods: Proteins of different molecular sizes and immunoglobulins were measured in paired CSF and plasma samples in children with falciparum malaria and either impaired consciousness, prostrate, or seizures.

Results: The ratio of CSF to plasma albumin $\left(\mathrm{Q}_{\mathrm{alb}}\right)$ exceeded the reference values in $42(51 \%)$ children. The CSF concentrations of the excitotoxic amino acid aspartate and many non-polar amino acids, except alanine, were above the reference value, despite normal plasma concentrations. IgM concentrations were elevated in $21(46 \%)$ and the IgM index was raised in $22(52 \%)$. Identical IgG oligoclonal bands were found in $9(35 \%)$, but only one patient had an increase in the CSF IgG without a concomitant increase in plasma indicating intrathecal synthesis of IgG.

Conclusions: This study indicates that the BBB is mildly impaired in some children with severe falciparum malaria, and this impairment is not confined to cerebral malaria, but also occurs in children with prostrate malaria and to a lesser extent the children with malaria and seizures. There is evidence of intrathecal synthesis of immunoglobulins in children with malaria, but this requires further investigation. This finding, together with raised level of excitotoxic amino acid aspartate could contribute to the pathogenesis of neurological complications in malaria.
\end{abstract}

\section{INTRODUCTION}

Plasmodium falciparum is one of the most common parasitic diseases of the central nervous system (CNS) [1], yet the pathogenesis remains poorly understood. Sequestration of the parasitized red blood cells in the microvasculature of the brain is thought to be the main pathogenetic factor in cerebral malaria (CM) [2], but how the intra-erythrocytic malarial parasites induce neuronal dysfunction without penetrating the cerebral tissue is unclear. The pathogenesis of less severe CNS manifestations such as prostration and seizures are similarly unknown.

Integrity of the blood brain barrier (BBB) may be important in understanding the cause of the neurological complications of falciparum malaria, in particular CM; since impair-

*Address correspondence to this author at the Kenya Medical Research Institute, Centre for Geographic Medicine Research (Coast), P. O. Box 230, Kilifi, Kenya; E-mail: cnewton@kilifi.kemri-wellcome.org ment of the BBB would allow substances produced by the intravascular parasites and by the host's response, to penetrate the brain parenchyma and impair function [2]. Breakdown of the BBB has been shown in murine models of neurological involvement of malaria [3], but the evidence in humans is not clear [4]. Studies in South East Asian adults with $\mathrm{CM}$ have shown that the $\mathrm{BBB}$ is able to exclude large molecules from the cerebrospinal fluid (CSF) [5,6], however no work has been reported on the transport of smaller molecules, such as amino acids. In contrast, autopsy studies in Vietnamese adults [7] and Malawian children [8] with CM demonstrated endothelial cell activation and disruption of intercellular junctions, suggesting BBB breakdown in areas of parasite sequestration. Furthermore, the Malawian children with CM had a significantly higher albumin index compared to the English controls [8]. Integrity of the BBB in less severe CNS manifestations of falciparum malaria has not been reported, and it is not clear if these less severe manifes- 
tations are caused by the same pathogenetic mechanisms as cerebral malaria.

Immunoglobulins and excitotoxins (compounds that overactivate receptors resulting in death of neurons) may also contribute to the neurological impairment in falciparum malaria. Neurological complications are immune mediated in mouse models of malaria [9]; and in one study in Brazilian adults, CM was thought to have features of vasculomyelinopathy [10], and intrathecal synthesis of immunoglobulins was found in a study of adult Thais [11], but the evidence from other studies is lacking. Increased concentrations of quinolinic acid, an excitotoxic compound, were found in the CSF of Kenyan children [12] and Vietnamese adults [13], but other excitotoxic mediators have not been reported. Finally petechial haemorrhages are seen in the brains of patients that have died with cerebral malaria, but cannot be detect in vivo. Ferritin is raised in intracerebral haemorrhages [14], and may detect petechial haemorrhages in life.

Thus we examined the integrity of the BBB in malaria by measuring proteins and amino acids with differing molecular sizes and physicochemical properties in CSF and plasma samples. Also we looked for evidence of intrathecal immunoglobulin synthesis, excitotoxins and neuronal damage with S-100 (astroglial damage) [15], Protein 14-3-3 (neuronal damage) [16], glial neurofilament heavy chain (astrocyte damage) [17] in Kenyan children with different neurological complications of falciparum malaria.

\section{METHODS}

\section{Study Setting}

The study was conducted at the Kenya Medical Research Institute (KEMRI) unit, at the Kilifi District Hospital on the coast of Kenya. Malaria transmission occurs throughout the year, with peak transmission after the rainy seasons of April to May and October to November [18].

\section{Patients}

Children with falciparum malaria had a lumbar puncture (LP) performed to exclude other CNS infections. The indications for LP were i) under the age of three years who were prostrated, defined as unable to sit unaided or cannot drink if less than 6 months [19]; ii) under the age of 2 years with history of convulsions, excluding those with previous history of febrile convulsions; iii) any impairment in consciousness; or iv) clinical suspicion of meningitis such as irritability, bulging fontanelle and neck stiffness. Children who had convulsions, or were unconscious on admission had LP delayed until they were neurologically stable [20].

Blood samples were collected by venepuncture within 10 minutes of LP, centrifuged and plasma extracted. For the amino acid samples, the plasma and CSF was snap frozen in liquid nitrogen and stored at $-80^{\circ} \mathrm{C}$ until analysis. For the measurement of the other proteins it was stored at $-20^{\circ} \mathrm{C}$.

A primary diagnosis of malaria was made if the child had a febrile illness with a peripheral asexual parasitaemia and no other cause was found for the fever. The neurological complications of malaria were classified as follows:

(i) Malaria with seizures $(\mathrm{M}+\mathrm{S})$ : history of seizures, or had seizures on presentation to hospital but had no impairment in consciousness between seizures. (ii) Malaria with Prostration (MP): inability to sit unsupported (greater than 8 months) or breastfeed (if less than 8 months).

(iii) Cerebral malaria (CM): a patient unable to localize a painful stimulus, and other causes of encephalopathy excluded [21].

These findings were compared to children with acute bacterial meningitis (ABM), an encephalopathy in which impairment of the $\mathrm{BBB}$ is established [22]. ABM is defined as definite (culture positive CSF) or probable (CSF white cell count $(\mathrm{WCC})>50$ cells $/ \mu 1$ with a blood:CSF glucose ratio $<0.67)[23]$.

\section{Laboratory Methods}

Thick and thin blood films were stained with Giemsa and examined for asexual forms of $P$. falciparum, with the parasite count reported per 100 white blood cells or 500 red blood cells and parasitaemia calculated from the concomitant white and red cell counts (Beckman/Coulter, UK).

The CSF leukocyte count was performed by manual count in a modified Neubauer counting chamber at $400 \mathrm{x}$ magnification. Gram stain was performed if the WCC was greater than 10 cells $/ \mu 1$. All CSF samples were cultured by inoculating $20 \mu \mathrm{C} \mathrm{CSF}$ on to $7 \%$ horse blood agar and $5 \%$ chocolate blood agar plates.

CSF total protein and albumin were used as conventional markers of blood brain barrier integrity [24]. We measured immunoglobulin $\mathrm{M}(\mathrm{IgM})$ and $\mathrm{G}(\mathrm{IgG})$ to look for immune activation. CSF protein s100-b was used as a marker of astrocytic activation. We assayed CSF ferritin as a marker for intracerebral bleeding and infection [25].

CSF total protein was measured by turbidimetry using benzethonium chloride [26]. Glucose was assayed on a GM7 analyzer (Analox Ltd UK). Albumin was measured using electroimmunoassay [27]. Plasma and CSF (IgM) were measured by sandwich enzyme-linked immunosorbent assay (ELISA). The IgM Index was calculated from CSF/plasma IgM divided by the $\mathrm{CSF} /$ plasma albumin ratio. Immunoglobulin $\mathrm{G}$ ( $\mathrm{IgG}$ ) oligoclonal bands were detected in plasma and CSF with isoelectric focusing in agarose followed by transfer to nitrocellulose membrane and immunodetection using goat anti-human IgG followed by horse-radish peroxidase conjugated rabbit anti-goat [28]. Ferritin [14] and s100b [29] were measured by sandwich ELISA. Glial neurofilament heavy chain was measured with a specific ELISA [30] and protein 14-3-3 was detected using Western blotting [31].

Amino acids were assayed using high performance liquid chromatography (HPLC) of paired samples of CSF and plasma. Samples were deproteinised by perchloric acid prior to analysis by HPLC using a system based on precolumn derivatisation with phenylisothiocyanite.

Reference intervals (RI) which included $95 \%$ of the normal values were obtained from the ranges used at the Institute of Neurology, London, UK and published ranges [24].

\section{Statistical Methods}

Clinical and laboratory data were double entered and verified using Foxpro for Windows Version 2.6 (Microsoft Corp. USA). Data were analysed using Stata Version 6.0 
(Stata Corporation, Texas, USA). Each child provided paired CSF and plasma samples, and the ratio of CSF to plasma provided an index of BBB integrity. We plotted the albumin quotient on an age dependent quotient diagram with hyperbolic discrimination lines (Reibergram). In order to interpret the results for the other proteins and amino acids, we compared the CSF values to reference ranges. The proportion of children with values above the RI in the different groups was compared using Fisher's exact test.

\section{Ethical Approval}

This study was approved by The National Ethical Committee of Kenya.

\section{RESULTS}

One hundred children were studied and 43 were classified as having malaria with seizures, 8 with malaria with prostration, 44 with cerebral malaria and five with $\mathrm{ABM}$
(Table 1). In the children with ABM, three cases were confirmed (Haemophilius influenzae in two and one Streptococcus pneumoniae) and the remainder had CSF WCC $>50$ cells/ $\mu 1$ with a blood:CSF glucose ratio $<0.6$.

All the lumbar punctures were performed within three days of admission. 54 were performed on the day of admission, 34 on the day following admission, and 9 and 3 respectively on the second and third day after admission. There were no significant differences in the values of the parameters measured and the day of sampling.

In the children with malaria, the median CSF WCC was 2 cells $\times 10^{9} / 1(90 \%$ central range $0-8)$. There was no evidence of an association between the proportion with CSF WCC $\geq 5$ cells $\times 10^{6} / 1$ and the malaria groups. The median CSF glucose in the children with malaria was $3.2(90 \%$ central range $1.0-4.9) \mathrm{mmol} / \mathrm{l}$. There was no evidence of an association between the WCC or CSF glucose and the malaria groups.

Table 1. Clinical and Laboratory Data of Children on Admission

\begin{tabular}{|c|c|c|c|c|}
\hline & $\begin{array}{c}\text { Malaria with } \\
\text { Seizures (MS) }\end{array}$ & $\begin{array}{c}\text { Malaria with } \\
\text { Prostration (MP) }\end{array}$ & $\begin{array}{c}\text { Cerebral } \\
\text { Malaria }(\mathrm{CM})\end{array}$ & $\begin{array}{c}\text { Acute Bacterial } \\
\text { Meningitis (ABM) }\end{array}$ \\
\hline $\mathrm{N}$ & 43 & 8 & 44 & 5 \\
\hline Age (months) ${ }^{\dagger}$ & $21.9(9.1-56.0)$ & $19.6(5.3-146.0)$ & $28.9(4.0-64.0)$ & $8.3(0.2-94.7)$ \\
\hline $\begin{array}{l}\text { Duration of history (days) } \\
1 \\
2 \\
3 \\
4 \text { or more }\end{array}$ & $\begin{array}{c}7(16 \%) \\
11(26 \%) \\
18(42 \%) \\
7(16 \%)\end{array}$ & $\begin{array}{l}0 \\
0 \\
3 \\
5\end{array}$ & $\begin{array}{l}9(20 \%) \\
11(25 \%) \\
13(30 \%) \\
11(25 \%)\end{array}$ & $\begin{array}{l}0 \\
1 \\
3 \\
1\end{array}$ \\
\hline $\begin{array}{cc}\text { Convulsions }^{\mathrm{a}} & \mathrm{Y} \\
& \mathrm{N}\end{array}$ & $\begin{array}{c}40(93 \%) \\
3(7 \%)\end{array}$ & $\begin{array}{l}1 \\
7\end{array}$ & $\begin{array}{l}34(77 \%) \\
10(25 \%)\end{array}$ & $\begin{array}{l}2 \\
3\end{array}$ \\
\hline $\begin{array}{cc}\text { Localise }^{b} & \mathrm{Y} \\
& \mathrm{N}\end{array}$ & $\begin{array}{c}43(100 \%) \\
0\end{array}$ & $\begin{array}{l}6 \\
2\end{array}$ & $\begin{array}{c}2(5 \%) \\
42(95 \%)\end{array}$ & $\begin{array}{l}2 \\
3\end{array}$ \\
\hline $\begin{array}{cr}\text { Prostrate } & \mathrm{Y} \\
& \mathrm{N}\end{array}$ & $\begin{array}{l}13(30 \%) \\
30(70 \%)\end{array}$ & $\begin{array}{l}4 \\
4\end{array}$ & $\begin{array}{c}38(86 \%) \\
6(14 \%)\end{array}$ & $\begin{array}{l}3 \\
2\end{array}$ \\
\hline $\begin{array}{l}\text { Blantyre Coma Score }[21] \\
5 \\
4 \\
3 \\
2 \\
1 \\
0\end{array}$ & $\begin{array}{c}14 \\
1 \\
1 \\
0 \\
1 \\
26\end{array}$ & $\begin{array}{l}4 \\
2 \\
0 \\
0 \\
0 \\
2\end{array}$ & $\begin{array}{c}2 \\
5 \\
5 \\
15 \\
9 \\
7\end{array}$ & $\begin{array}{l}0 \\
2 \\
1 \\
1 \\
0 \\
1\end{array}$ \\
\hline $\begin{array}{l}\text { Parasitaemia }(/ \mu \mathrm{l})^{\dagger} \\
\text { Haemoglobin }(\mathrm{g} / \mathrm{dl})^{\dagger} \\
\text { White Cell Count }(\times 10 \% /)^{\dagger}\end{array}$ & $\begin{array}{c}110,580(1062-797,040) \\
7.0(2.5) \\
10.6(6.0-19.7)\end{array}$ & $\begin{array}{c}179,560(175-442,860) \\
6.8(1.6) \\
18.5(4.8-28.3)\end{array}$ & $\begin{array}{c}94,060(972-1077,440) \\
6.9(2.1) \\
12.2(6.3-37.1)\end{array}$ & $\begin{array}{c}- \\
8.0(3.4) \\
15.7(4.6-30.9)\end{array}$ \\
\hline Blood glucose $(\mathrm{mmol} / \mathrm{l})^{\dagger}$ & $4.9(1.9-6.8)$ & $4.7(3.7-7.9)$ & $4.6(2.2-7.9)$ & $2.2(1.3-4.1)$ \\
\hline $\begin{array}{l}\mathrm{pH}^{*} \dagger \\
\text { Base deficit } \dagger\end{array}$ & $\begin{array}{c}7.3(0.1) \\
-8.2(-21.7--3.1)\end{array}$ & $\begin{array}{c}7.3(0.2) \\
-18.2(-23.1--2.3)\end{array}$ & $\begin{array}{c}7.3(0.2) \\
-9.4(-21.4--3.7)\end{array}$ & $\begin{array}{c}7.4(0.1) \\
-10.4(-13.5--6.8)\end{array}$ \\
\hline
\end{tabular}

${ }^{\dagger}$ Median $(90 \%$ central range).

${ }^{\ddagger}$ Mean (SD).

*Venous blood gas done on 61 patients.

a 3 developed seizures post admission.

${ }^{\mathrm{b}}$ Some patients fulfilled the criteria for cerebral malaria after admission. 


\section{The Integrity of the Blood Brain Barrier}

\section{Protein Analysis}

In the children with malaria, 19/93 (20\%) had CSF total protein concentrations greater than the reference interval (RI). The ratio of CSF to plasma albumin $\left(\mathrm{Q}_{\mathrm{alb}}\right)$, an index of BBB integrity, was above the RI in 42/82 (51\%) children [32] (Fig. 1). In the children with ABM, the proportions with CSF protein concentrations (Fisher's exact test $p=0.003$ ) and $\mathrm{Q}_{\mathrm{alb}}$ levels $(\mathrm{p}=0.031)$ above the RI, were significantly greater than in those with malaria (Table 2).

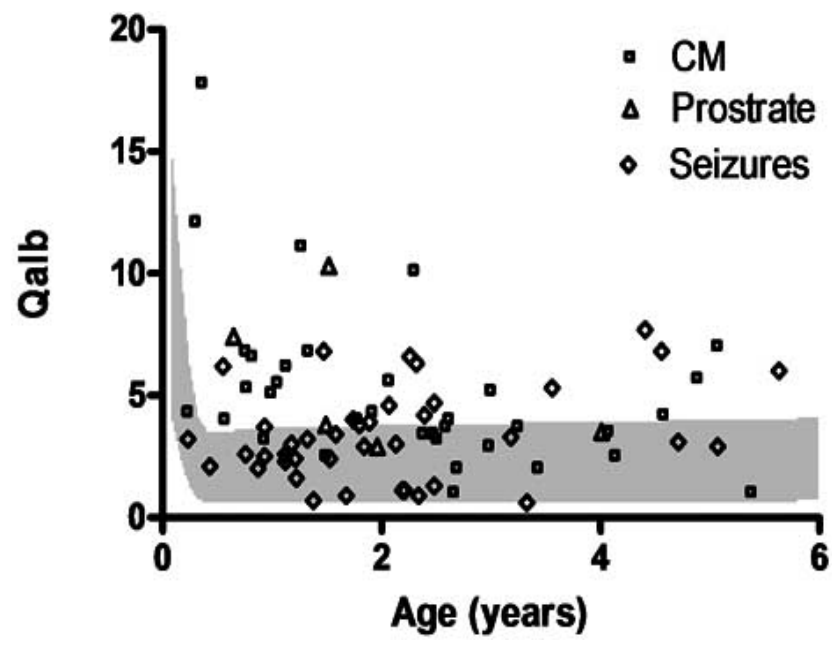

Fig. (1). $Q_{a l b}$ in children with malaria. Shaded area represents normal values for that age.

\section{CSF Amino Acids}

The amino acids that could be measured in the CSF from 10 patients with $\mathrm{CM}$ are shown in Fig. (2). Some of the valine peaks were missed because retention times were offset from the controls in the HPLC. The glutamate peaks could not be resolved under the HPLC conditions used, thus the data is omitted. Asparagine and tyrosine are not shown since the values were barely above the baseline noise, and these data were omitted.

The CSF concentrations of the excitotoxic amino acid aspartate were above the RI in all the children. Many nonpolar amino acids, except alanine, were above the RI (Fig. 2). The CSF concentrations of the neutral amino acids transported by sodium-independent $\mathrm{L}$ exchange transporter were raised, whilst none of those transported by the specific amino acid system $\mathrm{y}^{+}$or $\mathrm{B}^{0+}$ were raised [33].

\section{Evidence of Immunoglobulin Synthesis \\ CSF IgM and IgG Oligoclonal Bands}

Immunoglobulin $\mathrm{M}$ (IgM) concentrations were elevated in $21(46 \%)$ of 46 children with malaria in whom it was measured. We excluded samples with elevated red blood cells since the measurement of IgM in the CSF is sensitive to blood in this compartment. There was no evidence of a difference between the groups (Table 2). The IgM index was greater than 0.23 in $22(52 \%)$ of the 42 children with malaria in whom the plasma and CSF IgM concentrations were measured.

Identical immunoglobulin $\mathrm{G}$ oligoclonal bands (type 4) were detected in CSF and plasma in 4/12 of the $\mathrm{M}+\mathrm{S}$ group, and $4 / 11$ in the CM group. In one child with CM, the bands were detectable only in the CSF but not in plasma, indicative of intrathecal synthesis (type 2). Of the patients with ABM that were assayed, all 3 also had identical oligoclonal bands in CSF and plasma.

The CSF S100-b protein was above the reference range derived from European controls [24] in 3 (5\%) of 64 children with malaria.

Table 2. Cerebrospinal Fluid Parameters in Children with Malaria and Bacterial Meningitis

\begin{tabular}{|c|c|c|c|c|}
\hline & $\begin{array}{c}\text { Malaria with } \\
\text { Seizures (MS) }\end{array}$ & $\begin{array}{c}\text { Malaria with } \\
\text { Prostration (MP) }\end{array}$ & $\begin{array}{c}\text { Cerebral } \\
\text { Malaria }(\mathbf{C M})\end{array}$ & $\begin{array}{c}\text { Acute Bacterial } \\
\text { Meningitis (ABM) }\end{array}$ \\
\hline Maximum number $\dagger$ & 43 & 8 & 44 & 5 \\
\hline White cell count $(/ \mu \mathrm{l})+$ & $2(0-8)$ & $2(0-16)$ & $0(0-4)$ & $208(74-926)$ \\
\hline $\mathrm{CSF} /$ blood glucose ratio $<0.67$ & $15 / 41(37 \%)$ & $5 / 8(63 \%)$ & $22 / 44(50 \%)$ & $4 / 5(80 \%)$ \\
\hline CSF protein $>400 \mathrm{mg} / 1$ & $5 / 43(12 \%)$ & $3 / 8(38 \%)$ & $11 / 42(26 \%)$ & $3 / 4(75 \%)$ \\
\hline CSF albumin $>155 \mathrm{mg} / \mathrm{l}$ & $11 / 30(37 \%)$ & $2 / 6(33 \%)$ & $13 / 27(48 \%)$ & $1 / 1$ \\
\hline Qalb > RI for age [32] & $15 / 40(38 \%)$ & $3 / 5(60 \%)$ & $24 / 37(65 \%)$ & $3 / 4(75 \%)$ \\
\hline $\operatorname{IgM}>0.55 \mathrm{mg} / \mathrm{ml}$ & $8 / 19(42 \%)$ & $0 / 3$ & $13 / 24(54 \%)$ & $0 / 1$ \\
\hline IgM index $>0.23$ & $7 / 17(41 \%)$ & $0 / 3$ & $15 / 22(68 \%)$ & $0 / 1$ \\
\hline Ferritin $>12.0 \mathrm{ng} / \mathrm{ml}$ & $1 / 30(3 \%)$ & $1 / 6(17 \%)$ & $2 / 28(7 \%)$ & $1 / 1$ \\
\hline $\mathrm{S} 100$ protein $>0.55 \mathrm{ng} / \mathrm{ml}$ & $2 / 30(7 \%)$ & $0 / 6(0 \%)$ & $1 / 28(4 \%)$ & $1 / 1$ \\
\hline
\end{tabular}

$\dagger$ Not all children had all the tests. Percentages are calculated from the numbers who have had the tests performed. 
a) Non-polar amino acids.

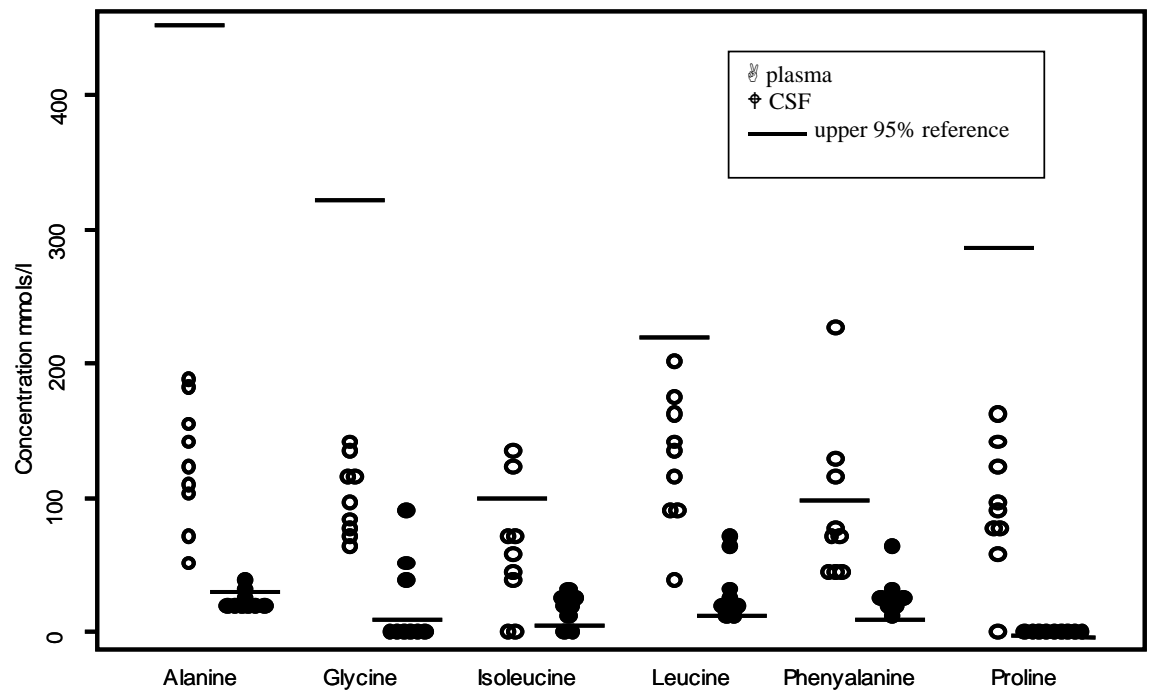

b) Polar amino acids.

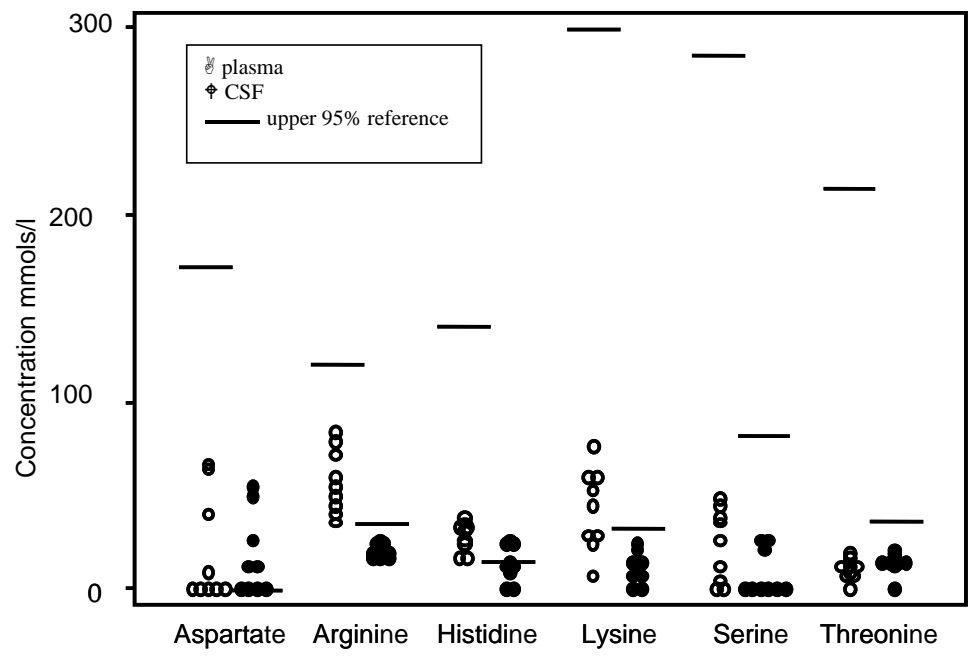

c) Polar and non-polar amino acids with high concentrations.

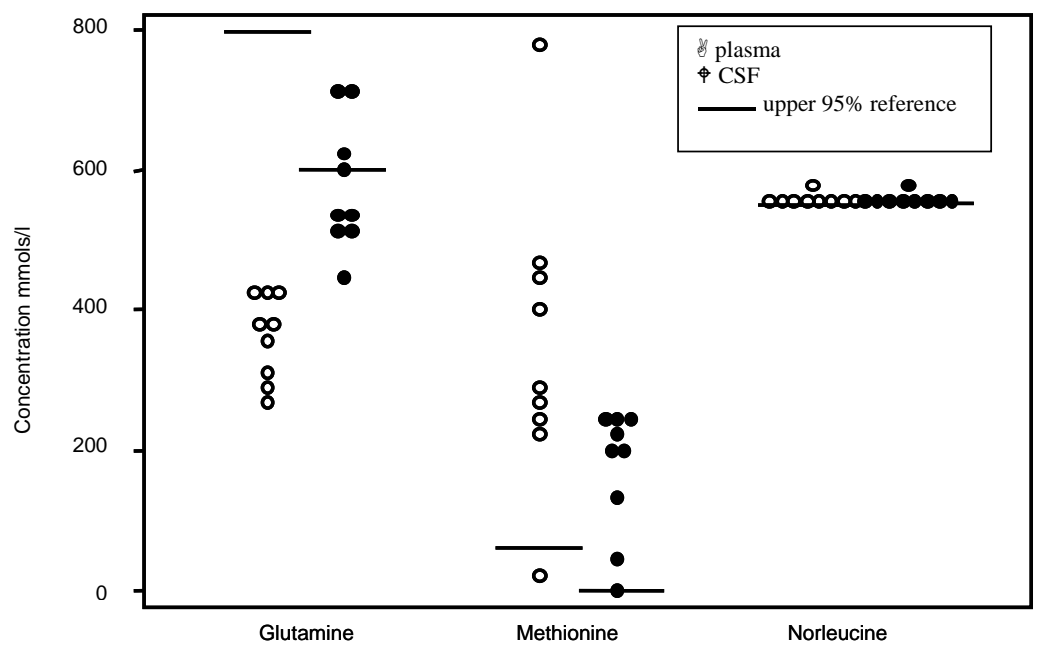

Fig. (2). Plasma and CSF concentrations of amino acids in children with malaria. 


\section{CSF Ferritin}

Five patients overall had ferritin concentrations above reference range [24]. The patient with bacterial meningitis had a CSF red cell count of $236 \mu 1$, and the patient with MS had $228 / \mu 1$. The remaining 3 (one MP and $2 \mathrm{CM}$ ) had CSF ferritin levels above the upper reference value at 18.2, 15.2 and $17.9 \mathrm{ng} / \mathrm{ml}$ respectively (reference value $12.0 \mathrm{ng} / \mathrm{ml}$ ) [24]

\section{Markers of Neuronal Damage}

Protein 14-3-3 was detected in 5/32 children with malaria, none of whom had neurological sequelae detected on discharge. All the neurofilament heavy chain $(n=27)$ titres were within the reference range derived from European controls [17].

\section{DISCUSSION}

This study indicates that the BBB is impaired in some children with severe falciparum malaria, but the impairment is less severe than that in bacterial meningitis. The impairment of the BBB is not confined to children with $\mathrm{CM}$, but also occurs in children who are prostrate or have seizures associated with malaria, and there is a possibility that mediators induced by parasites cross the BBB and cause neuronal dysfunction. Furthermore, there is production of excitotoxic amino acids in children with CM. There is also evidence of immune activation, since some children have raised IgM concentrations in the CSF and $52 \%$ had a raised IgM index [34].

Half of our patients had CSF parameters including total protein and albumin, and the albumin partition index within ranges considered to be normal. In contrast, the CSF findings in the ABM group showed significant increases in these parameters, indicative of BBB breakdown. However, our results suggest that there may be a milder degree of disruption of the BBB in malaria, since a proportion of patients in each malaria group had values that were just above the normal range. The mild increases in Qalb could be caused by transient impairment of the BBB following seizures [35]. We were unable to obtain CSF specimens from Kenyan children without CNS infections, and thus had to rely on reference intervals from European controls.

The high concentrations of IgM in the CSF and the raised IgM index in half of the children support immune activation in the CNS [36]. Since IgM may be raised if there is blood in the CSF, we cannot exclude the fact that petechial haemorrhages may have contributed to this finding. A lower proportion with raised IgM was reported in $2 / 21$ Zairean children with CM, but not in other forms of malaria [37]. Increased CSF IgM concentrations usually suggest active immune disease and increased IgM index is thought to be a good indicator of recent immunological stimulation [38]. The lack of oligoclonal bands detected in the CSF without an increase in plasma, except in one child with malaria and seizures, and the normal IgG index in Malawian children with CM [8] does not support intrathecal synthesis of immunoglobulins. All the CSF samples were obtained within 3 days after admission. This time may have been too short for the induction of IgG class of immunoglobulins [39] and if the LPs were performed later, increases in IgG may have been detected.

The CSF concentrations of S100 protein were below the upper limit of a RI derived from a European population, and there was no evidence of differences between the groups of malaria patients. The CSF amino acid assays performed in 10 patients with CM suggested that the BBB had increased permeability to all but one (alanine) of the non-polar, hydrophobic amino acids. The amino acids are smaller molecular weight compounds but have specific transport mechanisms that may be impaired in CM. Of the polar amino acids, the concentrations of excitotoxic neurotransmitter amino acids (aspartic acid) and the precursors of the other excitotoxic amino acids (glutamine and tyrosine) were increased. These results support excitotoxic mechanisms contributing to the pathogenesis of CM [12], possibly seizures and neurological sequelae.

One of the histological hallmarks of CM are ring and punctiform haemorrhages in the parenchyma of the brain [40]. We measured CSF ferritin as a potential marker of intracerebral bleeding and acute inflammation. The highest ferritin concentrations were associated with CSF red cell counts, but had no association with severity of disease. We found little biochemical evidence of neuronal injury by measuring protein 14-3-3 or axonal damage (neurofilament protein) as documented in Vietnamese adults with CM [41]. However we have recently found evidence of axonal damage (tau protein) and an association of S-100 with seizures after admission in Kenyan children with malaria [42].

The assessment of the BBB by the measurement of substances in the CSF at a single time-point needs to be interpreted with caution. CSF composition may not always reflect BBB function as it may be affected by changes in brain interstitial fluid originating in the brain itself, and the choroid plexus may also actively secrete substances into the CSF. However in malaria, the parasites are largely confined to the intravascular space, in particular the venules, and there is no evidence of sequestration in the choroid plexus [29].

Autopsy studies may afford a more direct look at the BBB, even though they only offer an assessment of the BBB in the terminal stages. Immunohistochemical studies in Vietnamese adults with CM showed, in contrast to our results, that there was widespread perivascular macrophage activation, and plasma protein leakage in patients with $\mathrm{CM}$, suggesting that there were functional changes to the BBB [7]. Autopsy studies in 8 children with $\mathrm{CM}$ also showed activation of endothelial cells and macrophages, and disruption of endothelial intercellular junctions in vessels containing sequestered PRBCs, but in contrast to the studies in adults, there was no gross leakage of plasma proteins [8].

\section{CONCLUSIONS}

Our findings suggest that the BBB in many children with severe malaria is able to exclude high molecular weight particles like albumin, but may be permeable to smaller compounds including the neurotransmitter amino acids associated with excitotoxic mechanisms. Furthermore there is evidence for intrathecal immunoglobulin synthesis in Kenyan children with falciparum malaria, but this needs to be investigated further.

\section{ACKNOWLEDGEMENTS}

This paper is published with the permission of the Director of KEMRI. The authors are grateful to the late Robert 
Surtees for reviewing the manuscript. This work is supported by KEMRI and the Wellcome Trust. Dr B Elford thanks the Leverhulme Trust for support. Dr J Berkley is a Wellcome Trust Research Training Fellow in Clinical Tropical Medicine (053439) and Prof C Newton is a Wellcome Trust Senior Fellow in Clinical Science (070114).

\section{REFERENCES}

[1] Newton CR, Warrell DA. Neurological manifestations of falciparum malaria. Ann Neurol 1998; 43(6): 695-702.

[2] Newton CR, Krishna S. Severe falciparum malaria in children: current understanding of pathophysiology and supportive treatment. Pharmacol Ther 1998; 79(1): 1-53

[3] Thumwood CM, Hunt NH, Clark IA, et al. Breakdown of the blood-brain barrier in murine cerebral malaria. Parasitol 1988; 96 (Pt 3): 579-89.

[4] Gitau EN, Newton CR. Blood-brain barrier in falciparum malaria. Trop Med Int Health 2005; 10(3): 285-292.

[5] Warrell DA, Looareesuwan S, Phillips RE, et al. Function of the blood-cerebrospinal fluid barrier in human cerebral malaria: rejection of the permeability hypothesis. Am J Trop Med Hyg 1986; 35 : 882-9.

[6] Brown HC, Chau TT, Mai NT, et al. Blood-brain barrier function in cerebral malaria and CNS infections in Vietnam. Neurology 2000; 55(1): 104-11.

[7] Brown H, Hien TT, Day N, et al. Evidence of blood-brain barrier dysfunction in human cerebral malaria. Neuropathol Appl Neurobiol 1999; 25(4): 331-340.

[8] Brown H, Rogerson S, Taylor T, et al. Blood-brain barrier function in cerebral malaria in Malawian children. Am J Trop Med Hyg 2001; 64(3-4): 207-213

[9] Grau GE, Piguet PF, Engers HD, et al. L3T4+ T lymphocytes play a major role in the pathogenesis of murine cerebral malaria. $\mathrm{J}$ Immunol 1986; 137: 2348-54

[10] Toro G, Roman G. Cerebral malaria. A disseminated vasculomyelinopathy. Arch Neurol 1978; 35: 271-5.

[11] Chapel HM, Warrell DA, Looareesuwan S, et al. Intrathecal immunoglobulin synthesis in cerebral malaria. Clin Exp Immunol 1987; 67: 524-30

[12] Dobbie M, Crawley J, Waruiru C, et al. Cerebrospinal fluid studies in children with cerebral malaria: an excitotoxic mechanism? Am J Trop Med Hyg 2000; 62(2): 284-90.

[13] Medana IM, Hien TT, Day NP, et al. The clinical significance of cerebrospinal fluid levels of kynurenine pathway metabolites and lactate in severe malaria. J Infect Dis 2002; 185(5): 650-6.

[14] Keir G, Tasdemir N, Thompson EJ. Cerebrospinal fluid ferritin in brain necrosis: evidence for local synthesis. Clin Chim Acta 1993; 216(1-2): 153-66

[15] Lins H, Wallesch CW, Wunderlich MT. Sequential analyses of neurobiochemical markers of cerebral damage in cerebrospinal fluid and serum in CNS infections. Acta Neurol Scand 2005; 112(5): 303-8.

[16] Berg D, Holzmann C, Riess O. 14-3-3 proteins in the nervous system. Nat Rev Neurosci 2003; 4(9): 752-62.

[17] Sjogren M, Blomberg M, Jonsson M, et al. Neurofilament protein in cerebrospinal fluid: a marker of white matter changes. J Neurosci Res 2001; 66(3): 510-6.

[18] Snow RW, Armstrong-Schellenberg JRM, Peshu N, et al. Periodicity and time-space clustering of severe childhood malaria on the coast of Kenya. Trans R Soc Trop Med Hyg 1993; 87: 386-90.

[19] Marsh K, Forster D, Waruiru C, et al. Indicators of life-threatening malaria in African children. N Engl J Med 1995; 332(21): 1399404

[20] Newton CR, Kirkham FJ, Winstanley PA, et al. Intracranial pressure in African children with cerebral malaria. Lancet 1991; 337: 573-6.
[21] WHO. Severe falciparum malaria. Trans R Soci Trop Med Hyg 2000; 94(suppl 1): S1-1-S1/74.

[22] Sharief MK, Ciardi M, Thompson EJ. Blood-brain barrier damage in patients with bacterial meningitis: association with tumor necrosis factor - alpha bit not interleukin -1 beta. J Infect Dis 1992; 166(2): 350-8.

[23] Berkley JA, Mwangi I, Ngetsa CJ, et al. Diagnosis of acute bacterial meningitis in children at a district hospital in sub-Saharan Africa. Lancet 2001; 357(9270): 1753-7.

[24] Fishman RA. Cerebrospinal fluid in diseases of the nervous system. $2^{\text {nd }}$ ed. Philadelphia: W.B.Saunders Company 1992.

[25] Milman N, Graudal NA, Olsen TS, et al. Cerebrospinal fluid ferritin in patients with meningitis and cerebral infarction or bleeding. Dan Med Bull 1993; 40(4): 490-92.

[26] Luxton RW, Patel P, Keir G, et al. A micro-method for measuring total protein in cerebrospinal fluid by using benzethonium chloride in microtiter plate wells. Clin Chem 1989; 35(8): 1731-4.

[27] McLean BN, Luxton RW, Thompson EJ. A study of immunoglobulin $\mathrm{G}$ in the cerebrospinal fluid of 1007 patients with suspected neurological disease using isoelectric focusing and the $\mathrm{Log} \mathrm{IgG}$ Index. A comparison and diagnostic applications. Brain 1990; 113 (Pt 5): 1269-89.

[28] Keir G, Luxton RW, Thompson EJ. Isoelectric focusing of cerebrospinal fluid immunoglobulin G: an annotated update. Ann Clin Biochem 1990; 27 (Pt 5): 436-43.

[29] Green AJ, Keir G, Thompson EJ. A specific and sensitive ELISA for measuring $\mathrm{S}-100 \mathrm{~b}$ in cerebrospinal fluid. J Immunol Methods 1997; 205(1): 35-41.

[30] Petzold A, Keir G, Green AJ, et al. An ELISA for glial fibrillary acidic protein. J Immunol Methods 2004; 287(1-2): 169-77.

[31] Green AJ, Thompson EJ, Stewart GE, et al. Use of 14-3-3 and other brain-specific proteins in CSF in the diagnosis of variant Creutzfeldt-Jakob disease. J Neurol Neurosurg Psychiatry 2001; 70(6): 744-8

[32] Eeg-Olofsson O, Link H, Wigertz A. Concentrations of CSF proteins as a measure of blood brain barrier function and synthesis of IgG within the CNS in 'normal' subjects from the age of 6 months to 30 years. Acta Paediatr Scand 1981; 70(2): 167-70.

[33] Hawkins RA, O'Kane RL, Simpson IA, et al. Structure of the blood-brain barrier and its role in the transport of amino acids. J Nutr 2006; 136(1 Suppl): 218S-226S.

[34] Ohman S, Ernerudh J, Forsberg P, et al. Improved formulae for the judgement of intrathecally produced $\operatorname{IgA}$ and $\operatorname{IgM}$ in the presence of blood CSF barrier damage. Ann Clin Biochem 1993; 30 (Pt 5): 454-62.

[35] Eeg-Olofsson O, Wigertz A, Link H. Immunoglobulin abnormalities in cerebrospinal fluid and blood in children with febrile seizures. Neuropediatries 1982; 13(1): 39-41.

[36] Armah HB, Wilson NO, Sarfo BY, et al. Cerebrospinal fluid and serum biomarkers of cerebral malaria mortality in Ghanaian children. Malar J 2007; 6: 147-7.

[37] Badibanga B, Dayal R, Depierreux M, et al. Etude des principaux facteurs immunologiques et de la barriere hemato- meningee au cours de la malaria cerebrale chez l'enfant en pays d'endemie (Zaire). Ann Soc Belg Med Trop 1986; 66: 23-37.

[38] Sharief MK, Thompson EJ. Immunoglobulin $M$ in the cerebrospinal fluid: an indicator of recent immunological stimulation. J Neurol Neurosurg Psychiatry 1989; 52(8): 949-53

[39] Felgenhauer K, Ackermann R, Schliep G. The process dynamics of viral and bacterial diseases of the central nervous system. J Neurol Sci $1980 ; 47(1): 21-34$.

[40] Turner G. Cerebral malaria. Brain Pathol 1997; 7(1): 569-82.

[41] Medana IM, Day NP, Hien TT, et al. Axonal injury in cerebral malaria. Am J Pathol 2002; 160(2): 655-66.

[42] Medana IM, Idro R, Newton CR. Axonal and astrocyte injury markers in the cerebrospinal fluid of Kenyan children with severe malaria. J Neurol Sci 2007; 258(1-2): 93-8. 